\title{
Technocratic Childbirth Models
}

\section{Kiran Regmi}

Professor, Department of Gynaecology \& Obstretics, Chair, Research Committee, Karnali Academy of Health Sciences (KAHS), Jumla, Nepal

Former Health Secretary, Government of Nepal

\section{Corresponding Author:}

\section{Dr. Kiran Regmi}

Email: regmikiran@gmail.com

\section{BACKGROUND}

Technology in childbirth is one of the most debatable topics around childbirth. The metaphor of the bodyas-machine (and the related image of the female body as a defective machine) eventually formed the philosophical foundations of contemporary technocratic childbirth model. 'Physicians, for instance, can present us with numerous examples of women who would have died had they not given birth in the hospital. What they refuse to see, however, is that they, and the women they deliver, all believe that childbirth is painful and dangerous - otherwise they would not be doing it in a hospital equipped with all the latest technology'. Their belief, then, is precisely what makes it so. 'It is believed that the bigger the hospital, and the bigger the intensive care baby unit, the safer the birth'2.

Medicalisation of childbirth is the ritual of technocratic model. WHO defines medicalisation as:

By medicalizing birth, i.e. separating a woman from her own environment and surrounding her with strange people using strange machines to do strange things to her in an effort to assist her (and some of this may occasionally be necessary), the woman's state of mind and body is so altered that her ways of carrying through this intimate act must also be altered and the state of the baby born must equally be altered. The result is that it is no longer possible to know what births would have been like before these

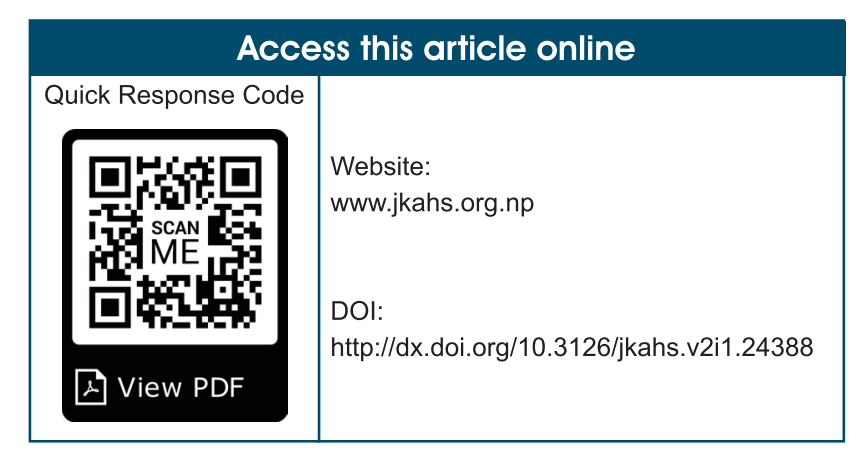

manipulations. Most health care providers no longer know what 'non-medicalized' birth is. This is an overwhelmingly important issue ${ }^{3}$.

As has been seen the medicalised approach to childbirth is based on the belief that every birth has a high potential for pathology ${ }^{4}$. According to this approach it is critical to tackle this pathology with medical or surgical interventions. Among the medical interventions, the active management of labour has become a common practice ${ }^{5}$. Active management is viewed as the health worker's domain. Connor ${ }^{6}$ argues that oxytocin, the artificial uterine muscle-contracting hormone that has been in use for active management of labour has potential side effects. These include rare cases of maternal deaths, intrapartum foetal deaths, uterine rupture, a salient factor in infant brain damage, and a slight increase in jaundice in the newborn. In addition, many birthing women dislike the feelings associated with such procedures. In one study $8 \%$ of mothers said labour hurt more, and over half would not want it again ${ }^{7}$. Another study surveyed hundred and fifty-nine new mothers and found that sixty-five of them said oxytocin drips were stressful ${ }^{8}$.

Several authors have expressed various opinions towards the surgical procedures in childbirth. 'Medical and social prejudices against women sidestepping 
their biblical sentence to painful childbirth are still with us and a consumer advocate states I do not believe that anyone has the right to demand women give birth vaginally' ${ }^{\prime}$. However, James ${ }^{10}$ has identified the emotional trauma attached to surgical procedures. He notes that surgery holds high-level significance for many people. It disrupts their personal, professional and economic lives, as well as their physical bodies. He adds that fear, anxiety, depression and a range of other emotions, accompany the patient to the surgical suite. Strong emotions, both happy and terrifying, are stored in our long-term memory. Some feelings, thoughts and images can be recalled with clarity years later. Frightening recollections may be pushed deep into the subconscious. While we do not consciously remember these impressions, they nevertheless color our thinking, feeling and behaviour in subtle ways.

It is important here to review some of the controversial and commonly used surgical procedures associated with childbirth, notably episiotomy and caesarean section. Episiotomies are the surgical enlargement of the vaginal orifice by an incision of the perineum during the last part of the second stage of labour. Episiotomies have become one of the most commonly performed surgical procedures in the world ${ }^{11,12}$. Unfortunately, this procedure brings with it considerable side effects, both emotional and physical.

Another common obstetric operation, caesarean section, has been part of human culture since ancient times (3000 B.C. in Egypt). There are tales in both Western and non-Western cultures of this procedure resulting in live mothers and offspring ${ }^{13}$. Despite rare references to the operation on living women, the initial purpose was essentially to retrieve the infant from a dead or dying mother. Above all, it was a measure of last resort, never intended to preserve the mother's life. It was not until the 19th century that the possibility of saving the mother really came within the grasp of the medical profession. Caesarean sections have since become among the most commonly performed surgical procedures. For example, France currently has a national cesarean section rate of $30 \%{ }^{14}$, while the combined operative and instrumental delivery rate in Spain is $40 \%{ }^{12}$. However, 'we should be concerned, not at what the caesarean section rate should be but at what the true section rate is now and why ${ }^{15}$ ? The tales of pain, trauma and injuries inspire little confidence in attempting a vaginal delivery for many women ${ }^{16}$. These reasons are understandable in a culture where medical intervention is a normal occurrence and caesarean sections are considered a safe alternative.

During its evolution, caesarean section has meant different things, to different people, at different times. The indications for it have changed dramatically from the ancient to the modern times ${ }^{17}$. The most quoted indication of caesarean section is the dictum of 'once caesarean section forever caesarean sections' has been disproved by some studies. Studies indicate that when a woman attempts to have a vaginal delivery after having a past caesarean section, the odds that her baby will die during labour, or soon thereafter, are quite low $^{18}$. Moreover, 'psychological trauma associated with these surgical procedures is even so noteworthy ${ }^{\prime 12}$. Caesarean sections leave a woman with a number of emotions that do not seem to be understood, nor how they should be addressed ${ }^{19}$. Women who have a caesarean section often report feeling dehumanized, humiliated and distressed by the experience, and this often has a profoundly adverse effect on their future lives and that of their babies.

While childbirth technology is blessing, it could be curse as well in women's lives. Hence, the most difficult task for the 21 st centurion obstetrician is that of rationalizing childbirth technology.

\section{REFERENCES}

1. McClean J, Turnbull D, McGinley M. Can childbirth be changed? Offering women a choice', British Journal of Midwifery 1999; 7(10):622-626

2. Hodgson D. 'A colonial lexicon of birth ritual, and mobility in the Congo', Journal of Social History 2001;35(3):505

3. World Health Organization (WHO), as quoted by Marsden Wagner, MD, in his article, The Active Management of Labour 
4. Jordan B. Cosmopolitan obstetrics: Some insights from the training of traditional midwives', Social Science and Medicine 1989;28(9):925-944

5. Kitzinger J. The desexing of birth; some effects of professionalization of care; the godsibs; what matters to women--their words. Innovations in Perinatal care: assessing Benefits and Risks', 9th Conference Presented by Birth, San Francisco 1990.

6. Connor M. Midwifery for all or midwifery for none', Midwifery Matters 2000;87: 3-4

7. Crowther C. Prolonged labor', in A Guide to Effective Care in Pregnancy and Childbirth, eds M. Enkin., M.J. Keirse., \& I. Chalmers, Oxford, Oxford University Press. 1989

8. Simkin P. Stress, pain and catecholamines in labor': part 1. A review. Birth 1986;13(4):227233.

9. Showlater E, Griffen A. All women should have a choice and Bastian Health has become secondary to a sexually attractive body', British Medical Journal1999;319 (7222):1397, 1999.

10. James J. Caesarean section for fetal distress. British Medical Journal 2001; 322:1316-1317.

11. Lede R, Belizan J. Is routine use of episiotomy justified. Americian Journal of Obstet Gynecol 1996:174:1399-1402.

12. Wagner M. Technology in Birth: First Do No Harm, Midwifery Today 2000; I
13. Neel, J. 2001, 'Medico-legal pressure, MDs' lack of patience cited in caesarean epidemic. Obstetric and Gynecology News2001; 22:10.

14. Enfants L, Francombe C. Caesarean section in Britain and the United States: 12-24\%, is either the right rate. Social Science and Medicine2000; 37:10.

15. Robson MS. Classification of caesarean sections. Fetal and Maternal Medicine Review 2001;12(1):23-39.

16. Turnbull DA, Wilkinson C. Women's role and satisfaction in the decision to have a caesarean section. Medical Journal of Australia 2000;172(1):46.

17. Al-Mufti R, McCarlin A, Fisk M. Survey of obstetricians' personal preference and discretionary practice', European Journal Obstet Gynecol Reprod Biol 1997;73(1):1-9.

18. Meakin S. Midwifery consultant posts: a necessary intervention', British Journal of Midwifery 2000;8(4):251.

19. Fisher J. Adverse psychological impact of operative obstetric interventions: a prospective study', American and Newzeland Journal of Psychiatry 1997;31:728-738

\section{How to cite this article?}

Regmi K. Technocratic Childbirth Models. Journal of Karnali Academy of Health Sciences. 2019;2(1):1-3

Conflict of Interest: None Source of Support: None 